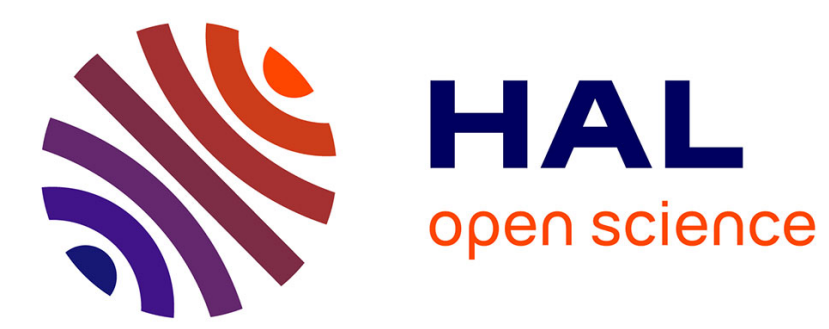

\title{
INFRARED FIBRE OPTICAL COMPONENTS FOR DIODE LASER TRACE GAS ANALYZERS
}

\author{
R. Grisar, J. Anders, M. Knothe, W. Riedel
}

\section{To cite this version:}

R. Grisar, J. Anders, M. Knothe, W. Riedel. INFRARED FIBRE OPTICAL COMPONENTS FOR DIODE LASER TRACE GAS ANALYZERS. Journal de Physique IV Proceedings, 1991, 01 (C7), pp.C7-699-C7-702. 10.1051/jp4:19917187 . jpa-00250866

\section{HAL Id: jpa-00250866 https://hal.science/jpa-00250866}

Submitted on 1 Jan 1991

HAL is a multi-disciplinary open access archive for the deposit and dissemination of scientific research documents, whether they are published or not. The documents may come from teaching and research institutions in France or abroad, or from public or private research centers.
L'archive ouverte pluridisciplinaire HAL, est destinée au dépôt et à la diffusion de documents scientifiques de niveau recherche, publiés ou non, émanant des établissements d'enseignement et de recherche français ou étrangers, des laboratoires publics ou privés. 


\title{
INFRARED FIBRE OPTICAL COMPONENTS FOR DIODE LASER TRACE GAS ANALYZERS
}

\author{
R. GRISAR, J. ANDERS, M. KNOTHE and W.J. RIEDEL \\ Fraunhofer-Institut fuer Physikalische Messtechnki (IPM), Heidenhofstrasse 8, D-7800 Freiburg, \\ Germany
}

\begin{abstract}
An IR diode laser spectrometer for fibre component characterization was set up. IR fluoride glass fibre samples with well-defined angles were prepared and preliminary coupling experiments were performed with special attention paid to minimize residual back reflexion by the fibres as a prerequisite for fibre application in infrared diode laser trace gas analyzers.
\end{abstract}

\section{1.- Introduction}

Infrared fibres and fibre components such as multiplexers and beam splitters can lead to more compact and reliable infrared diode laser gas analyzers $/ 1 /$. They also may prevent influence of unwanted atmospheric absorption within the system optics, e.g. in analyzing water vapour traces in ultrapure process gases. Fibres can be an alternative to a vacuum case for the optics. On the other hand, diode laser systems are extremely sensitive to optical feedback as low as 0.00001 and spurious reflection of fibre elements at these levels can not be predicted. A current project carried out in our laboratory is devoted to consequences of infrared fibre component inserted into diode laser trace gas analyzers. First experimental results will be reported.

\section{2.- Experimental setup}

The optics of the diode laser spectrometer for IR fibre component testing are plotted in Fig. 1. A lead-salt laser is kept at $T>80 \mathrm{~K}$ by a compact liquid nitrogen dewar and stabilized to $+/-3 \mathrm{mR}$. Imaging elements are gold-coated aspherical mirrors with nearly diffraction limited performance $/ 2 /$, comprising ellipsoids to transform the laser beam aperture from $f / 2$ to $f / 7$, and toroids for collimation. Intermediate foci enable fast alignment by inserting a visible point source, an eyepiece or a a highresolution miniature monochromator $/ 2 \%$. The beam numerical aperture with a maximum value of 0.2 is controlled by a variable diaphragm in the parallel beam. A reference beam is generated by a dielectric beam splitter. The fibre sample under investigation is inserted between two foci in the test beam. Room-temperature PbSe detectors can be inserted at various intermediate foci positions.

By a 90 degrees beam splitter rotation, the back reflex from the fibre can be quantified within the reference channel. Fibre ends are supported by rotation stages and correct positions are controlled by an eye piece in an intermediate focus. Near- and far-field distributions of fibres can be recorded with one fibre end mounted in a scanning device developed within a infrared diode laser development project in our laboratory. Electronics comprise temperature controller and current supply for pulsed laser operation with millisecond pulse duration. Transmission, reference and reflection signals can be alternatively processed by a boxcar integrator.

standard infrared fluoride multi-mode fibre samples with 100 and 200 um core diameter 


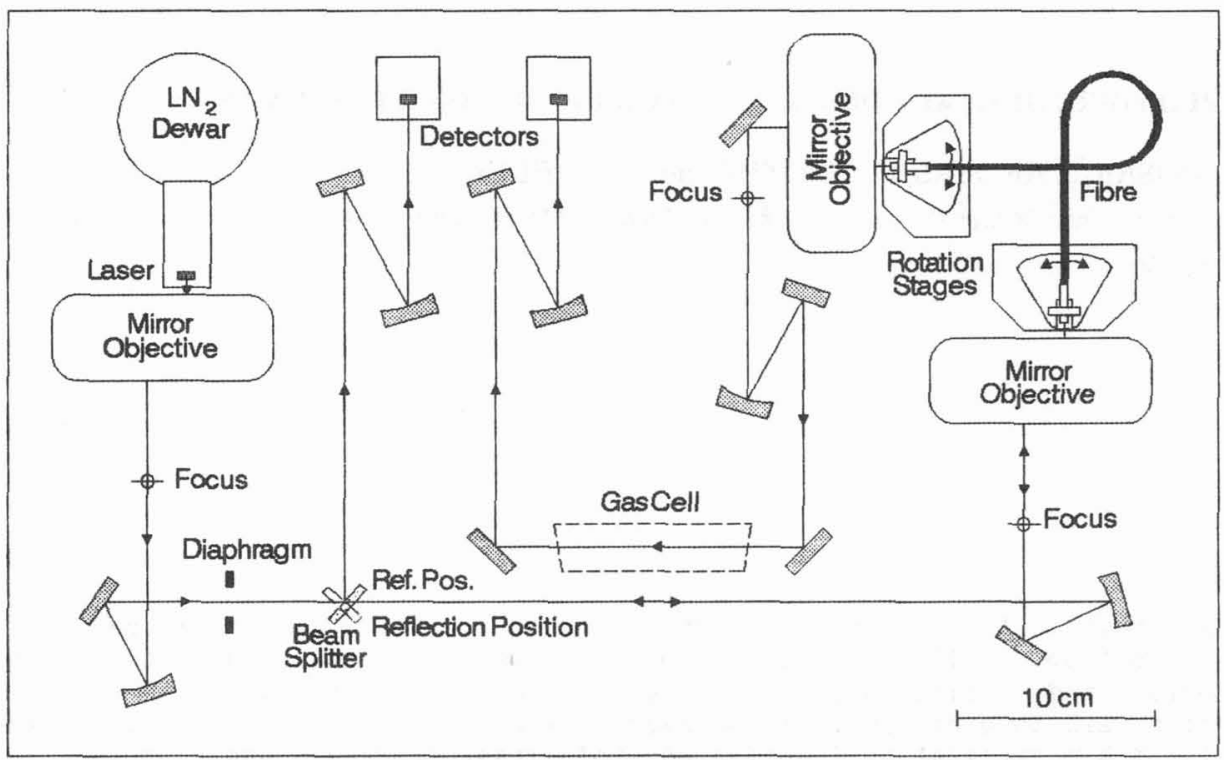

Flg. 1: Optical setup for infrared fibre component testing with lead-salt diode lasers

were supplied by Le Verre Fluoré, Vern-sur-Seiche, France. Fibre ends, glued into soft metal alloy cylinders, were ground and polished with abrasive paper down to a grain size of 1 um. By a specially developed tool, polishing could be performed at well-defined angles up to 20 degrees off the fibre axis normal.

\section{3.- Preliminary Results}

The first results reported here are rather intended for demonstration of the setup characteristics, than for a closer study of fibre properties which will be carried out in the future. Laser wavelengths were 4.40 and $3.87 \mathrm{um}$. Fig. 2 shows transmitted and reflected power versus incident angle for a 200 um core fibre cut at 15 degrees

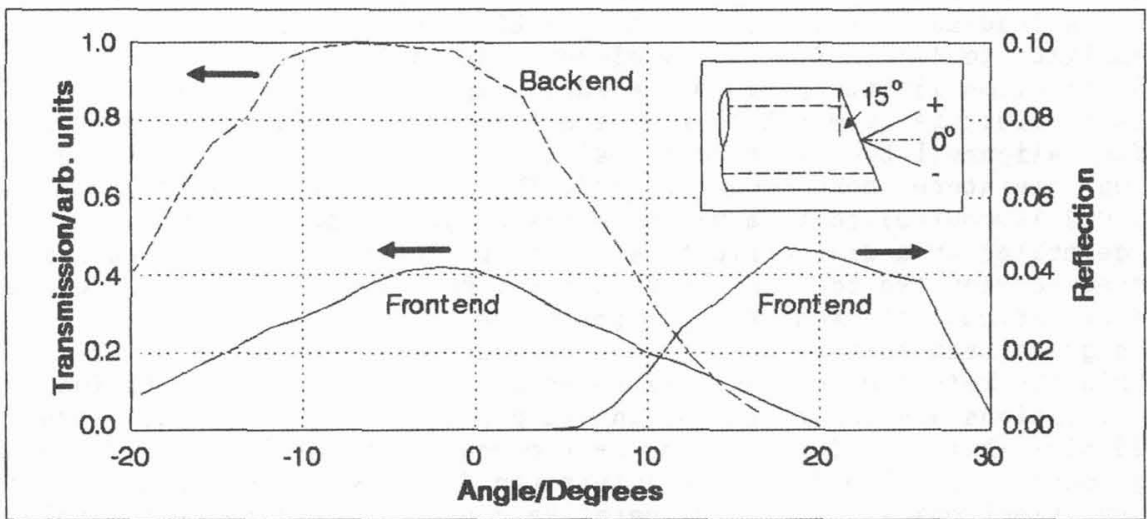

Fig.2: Transmission and reflection signals versus angular orientation of fibre ends (200 $\mathrm{\mu m}$ core diameter, both ends cut at 15 degrees) 
at both ends. Optimum coupling is attained at -2 degrees $(-8$ degrees for geometrical optics), the reflected power peaks at +18 degrees, close to the expected +15 degrees, and is below the present detection limit (0.0005 of the incoming intensity) at optimum coupling. Further shown is the transmission signal with the fibre back end rotated. The remote end reflex was below the detection limit. For perpendicular cut fibre ends, front and back end reflection were 0.0452 and 0.0082 of the incident power on the front end. The latter corresponds to a reflectivity of 0.04 (calculated value for $\mathrm{n}=1.51: 0.041)$. The back end reflex was clearly identified, the signal dropping by about a factor of ten upon wetting the surface with water as a nearly index-matched $(n=1.34)$ liquid absorber. Normalization to incident power was obtained by observing the reflection of a gold sheet mirror in contact to the remote fiber end.

Fig. 3 gives incident and transmitted power for a 200 un core fibre. The transmitted power increases up to the maximum beam diameter of $16 \mathrm{~mm}$, which corresponds to a 0.2 numerical aperture at the fibre. The ratio of transmitted and incident power attains a maximum at appr. $4 \mathrm{~mm}$ bean diameter. At lower diameters, the diffraction-limited focus size exceeds the fibre core diameter.

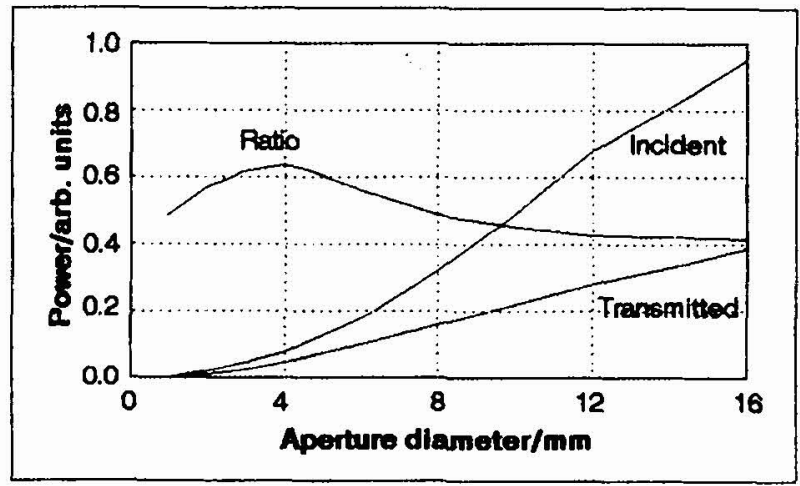

Flg.3: Coupling efficiency versus beam aperture

The far-field distribution of a 100 um core fibre is plotted in Fig. 4. The left side gives a two-dimensional scan with nine grey scale steps and the right side line scans

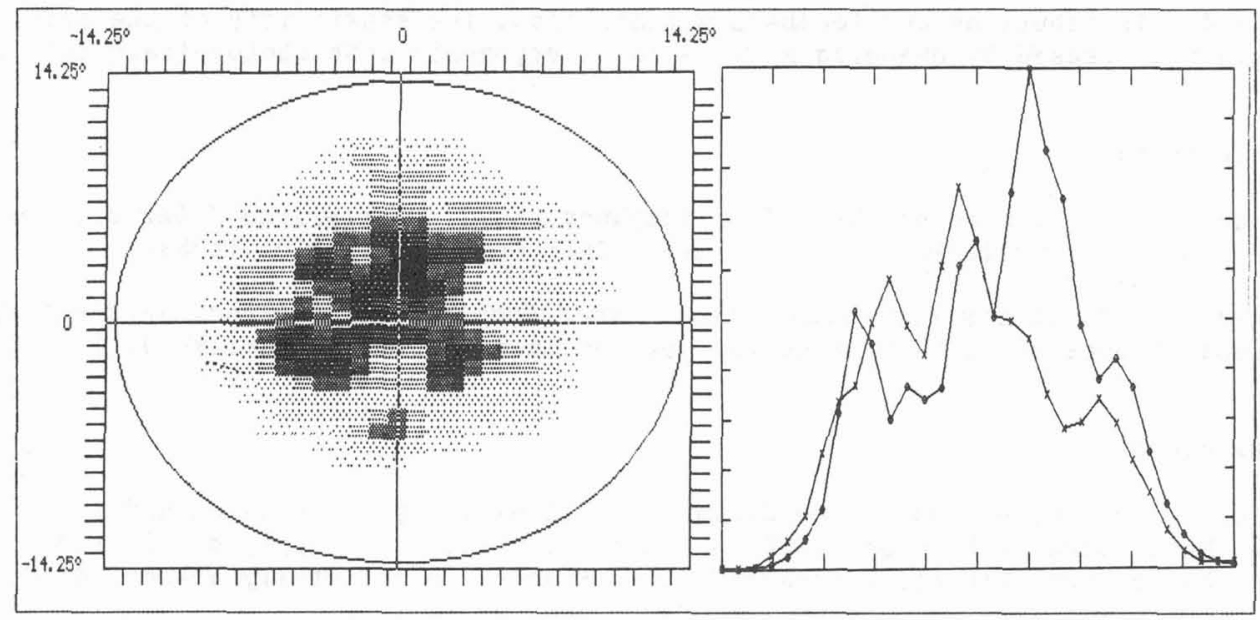

Fig.4: Far-field intensity distribution of a $100 \mathrm{~km}$ core fibre; left side: two-dimensional scan with 8 grey scale steps; right side: line scans along $x$ - and $y$-axis 
along $x$ - and $y$-axis. The multi-lobed structure depends on coupling conditions at the fibre input side. The dependence on laser mode structure, aperture, coupling and other fibre parameters needs further investigation.

Fig. 5 is a coarse attenuation experiment for a 100 um core fibre at two wavelengths with fibres cut at 15 degrees at both ends and detector signals behind 46 and $161 \mathrm{~cm}$ samples. Interpolation of the detector signals leads to attenuation valuess of 1.2 and $1.8 \mathrm{db} / \mathrm{m}$ for 3.87 and $4.40 \mathrm{um}$, and coupling losses in the order of $4 \mathrm{db}$. For $a$ wavelength of $3.87 \mathrm{um}$, the value is distinctly higher than specified $(0.15 \mathrm{db} / \mathrm{m})$. The accuracy of our measurement, however, is rather poor and experiments should be repeated with longer fibre samples, which vere not available to us so far.

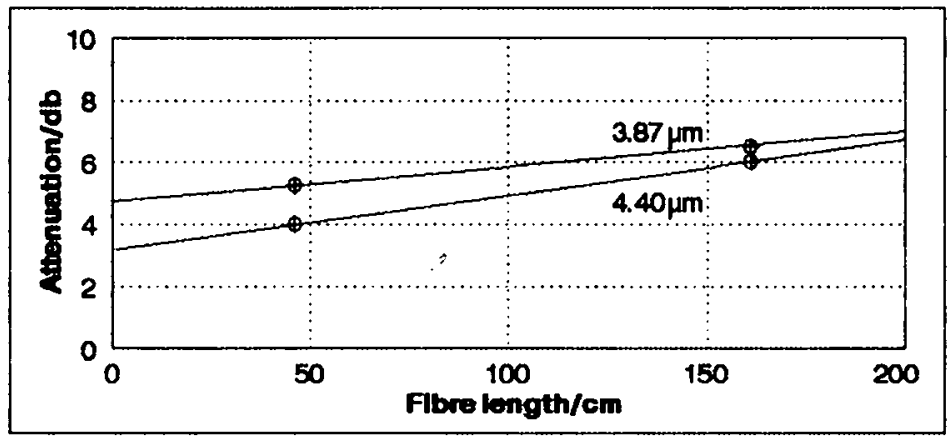

Fig.5: Coupling loseses and attenuation of a $200 \mu \mathrm{m}$ core fibre at two different wavelengths

\section{4.- Conclusions}

The results presented above demonstrate the capabilities of the infrared fibre characterisation setup with lead-salt diode laser sources described at the beginning. Application of infrared fibres in diode laser gas analyzers looks promising with respect to their feedback properties, when properly cut at larger angles. It is planned to carry out detailed investigations on fluoride multi- and monomode fibre samples, couplers and multiplexers under development at Le Verre Fluoré for an increased ravelength range up to $5 \mathrm{um}$. Points of interest will be attenuation, coupling losses, far-field distributions and feedback minimization. The sensitivity of the setup will be further increased by changing $\mathrm{PbSe}$ cells to cryogenic InSb photovoltaic detectors.

\section{5.- References}

11/ Kuznetsov, A I, Nadezhdinski, A I, Stepanov, E V, Computerized fiber-optic system for gas analysis based on diode lasers, SPIE Proc., vol. 1201 (1989).

/2/ Riedel, J, Optics for Tunable Diode Laser Spectrometers, Proc. SPIE's International Symposium on Laser Spectroscopy, OE Lase '91, to be published.

\section{Acknowledgments}

This work was sponsored by the German Federal Ministry of Research and Development within the EUROTRAC subproject JETDLAG under No. $07 \mathrm{EU} 732$. Supply of fluoride fibre samples by Le Verre Fluoré, Vern-sur-Seiche, France, is gratefully acknowledged. 